\title{
Estimating the effect of winter cover crops on nitrogen leaching using cost-share enrollment data, satellite remote sensing, and Soil and Water Assessment Tool (SWAT) modeling
}

W.D. Hively, S. Lee, A.M. Sadeghi, G.W. McCarty, B.T. Lamb, A. Soroka, J. Keppler, I.-Y. Yeo, and G.E. Moglen

\begin{abstract}
This study employed a novel combination of data (winter cover crop [WCC] costshare enrollment records, satellite remote sensing of wintertime vegetation, and results of Soil and Water Assessment Tool [SWAT] water quality simulations) to estimate the environmental performance of WCC at the watershed scale, from 2008 through 2017, in the Tuckahoe Creek watershed, located within the Choptank River basin. The Choptank River is a tributary of the Chesapeake Bay, and, as a focus watershed for the USDA's Conservation Effects Assessment Project, has been the subject of considerable study assessing linkages between land use and water quality. Farm enrollment data from the Maryland Agricultural Cost Share (MACS) program documented a large increase in the use of WCC within the Tuckahoe Creek watershed during the study period, rising from $27 \%$ of corn (Zea mays L.) fields and 9\% of soybean (Glycine max L.) fields in 2008 to $89 \%$ of corn fields and $46 \%$ of soybean fields in 2016. Satellite remote sensing of wintertime ground cover detected increased wintertime vegetation following corn crops, in comparison to full season and double cropped soybean, consistent with patterns of cover crop implementation. Although interannual variation in climate strongly affected observed levels of vegetation, with warm winters resulting in increased vegetative cover, a 30-year analysis of wintertime greenness revealed significant increases in wintertime vegetation associated with increased adoption of WCC. The MACS WCC enrollment data were combined with output from the SWAT model, calibrated to streamflow and nutrient loading from the Upper Tuckahoe watershed, to estimate water quality impacts based on known distribution of cover crop species and planting dates (2008 to 2017). Results indicated a $25 \%$ overall 10 -year reduction in nitrate $\left(\mathrm{NO}_{3}^{-}\right)$leaching from cropland attributable to cover crop adoption, rising to an estimated 38\% load reduction in 2016 when $64 \%$ of fields were planted to cover crops. Results suggest that increased environmental benefits would be achieved by shifting agronomic methods away from late-planted wheat (Triticum aestivum L.), which comprised $34.7 \%$ of all WCC planted between 2008 and 2017.
\end{abstract}

Key words: CEAP_Choptank — cover crops — remote sensing - SWAT — water quality

Winter cover crops (WCC) have been identified as one of the most cost-effective conservation practices for reduction of agricultural nitrogen $(\mathrm{N})$ pollution in the Chesapeake Bay watershed (McCarty et al. 2008; Ator and Denver 2012). Due to the high efficiency of WCC in reducing nitrate $\left(\mathrm{NO}_{3}^{-}\right)$loads, both federal and state governments provide cost-sharing programs to encourage local farmers to adopt WCC (McCarty et al. 2008), and the state of summer row crops such as corn (Zea mays L.), soybean (Glycine $\max$ L.), and vegetables. As they grow, the WCC take up N that would otherwise be vulnerable to leaching over the winter, protect the soil from raindrop impact and erosion, and promote soil health (Hively et al. 2009; Sharma et al. 2018). The cover crops are typically terminated the following spring to release nutrients for the subsequent cash crop. Because they help to meet important environmental targets, cover crops are strongly promoted by agricultural conservation agencies in the Chesapeake Bay region, and their use on farms has rapidly increased over the past decade. However, on-farm performance has been shown to be highly variable (Hively et al. 2009), and the effects on water quality at the landscape scale are not well quantified.

The Choptank River watershed, located in Maryland and Delaware on the Eastern Shore of the Chesapeake Bay (figure 1), has been a focus watershed for the USDA Conservation Effects Assessment Project (CEAP). The Choptank is one of 11 major rivers that drain to the Chesapeake Bay, and it is designated as impaired by excess nutrients and sediment, largely derived from agricultural runoff. Agricultural production is primarily poultry

$W$. Dean Hively is a research physical scientist with the US Geological Survey (USGS), Lower Mississippi-Gulf Water Science Center, Beltsville, Maryland. Sangchul Lee is a postdoctoral associate with the Department of Environmental Sciences and Technology, University of Maryland, College Park, Maryland. Ali M. Sadeghi is recently retired from the USDA Agricultural Research Service (ARS), Hydrology and Remote Sensing Laboratory, Beltsville, Maryland. Gregory W. McCarty is a soil scientist at the USDA ARS, Hydrology and Remote Sensing Laboratory, Beltsville, Maryland. Brian T. Lamb is a PhD candidate with the Department of Earth and Atmospheric Sciences, The City College of New York, City University of New York, New York, New York. Alex Soroka is a research physical scientist with the USGS, Maryland-Delaware-District of Columbia Water Science Center, Baltimore, Maryland. Jason Keppler is program manager for watershed implementation at the Maryland Department of Agriculture, Annapolis, Maryland. In-Young Yeo is professor of engineering at the School of Engineering, Faculty of Engineering and Built Environment, The University of Newcastle, Callaghan, NSW, Australia. Glenn E. Moglen is research director at the USDA ARS, Hydrology and Remote Sensing Laboratory, Beltsville, Maryland. 
production, along with large-scale corn, soybean, and winter small grain production and some dairy. The Choptank River watershed has been a focus area for CEAP Watershed and CEAP Wetland research since 2004 and 2008, respectively. Over this period, various publications detailing the linkages between landscape and water quality outcomes were generated, including such diverse subjects as fate and transport of nutrients and trace organic contaminants in 15 monitored subwatersheds (McCarty et al. 2008; Hively et al. 2011; Nino De Guzman et al. 2012; McCarty et al. 2014) as well as in the Choptank River estuary (Whitall et al. 2010); the effects of current and prior converted wetland areas on nutrient loading (Denver et al. 2014; Hunt et al. 2014; Sharifi et al. 2016; Li et al. 2017; Lee et al. 2017a, 2018a); use of remote sensing to map water use, wetland characteristics, and wetland connectivity to stream networks (Lang et al. 2012a, 2012b; Fenstermacher et al. 2014; Huang et al. 2014; Sun et al. 2017; Jones et al. 2018; Yeo et al. 2019a, 2019b); the use of remote sensing to map crop residue and tillage intensity (Hively et al. 2018, 2019; Quemada et al. 2018); modeling of nutrient transport, WCC, and climate change impacts on water quality using the Soil and Water Assessment Tool (SWAT; Yeo et al. 2014; Lee et al. 2016, 2017b, 2017c, 2018b, 2018c, 2018d); and the use of remote sensing to measure WCC conservation performance at the landscape scale (Hively et al. 2009, 2015; Hunt et al. 2010, 2011; Prabhakara et al. 2015).

Because the area of the Eastern Shore surrounding the Choptank River is well studied, comprehensive data sets of agricultural land use, water quality, and streamflow provided an excellent opportunity for model calibration and validation to support the investigation of WCC impacts on nutrient loading to streams. SWAT is a widely used hydrologic and water quality model that was developed to simulate the effects of changing land use and climate variability on watershed processes (Arnold et al. 1998). The model first divides a watershed into subwatersheds based on drainage network structure, and each subwatershed is then further divided into hydrologic response units (HRUs) by superimposing land cover, slope, and soil type within each given subwatershed. Thus, SWAT runs on an HRU concept that serves as the basis for representing homogeneous areas within each subwatershed. SWAT

\section{Figure 1}

Map of the Choptank River watershed, Maryland/Delaware, showing the boundaries for Upper Tuckahoe and Greensboro subwatersheds, along with a 2017 Cropland Data Layer (CDL) map of summer crop type showing the extent of the Tuckahoe Creek HUC8 watershed (\#02130405).

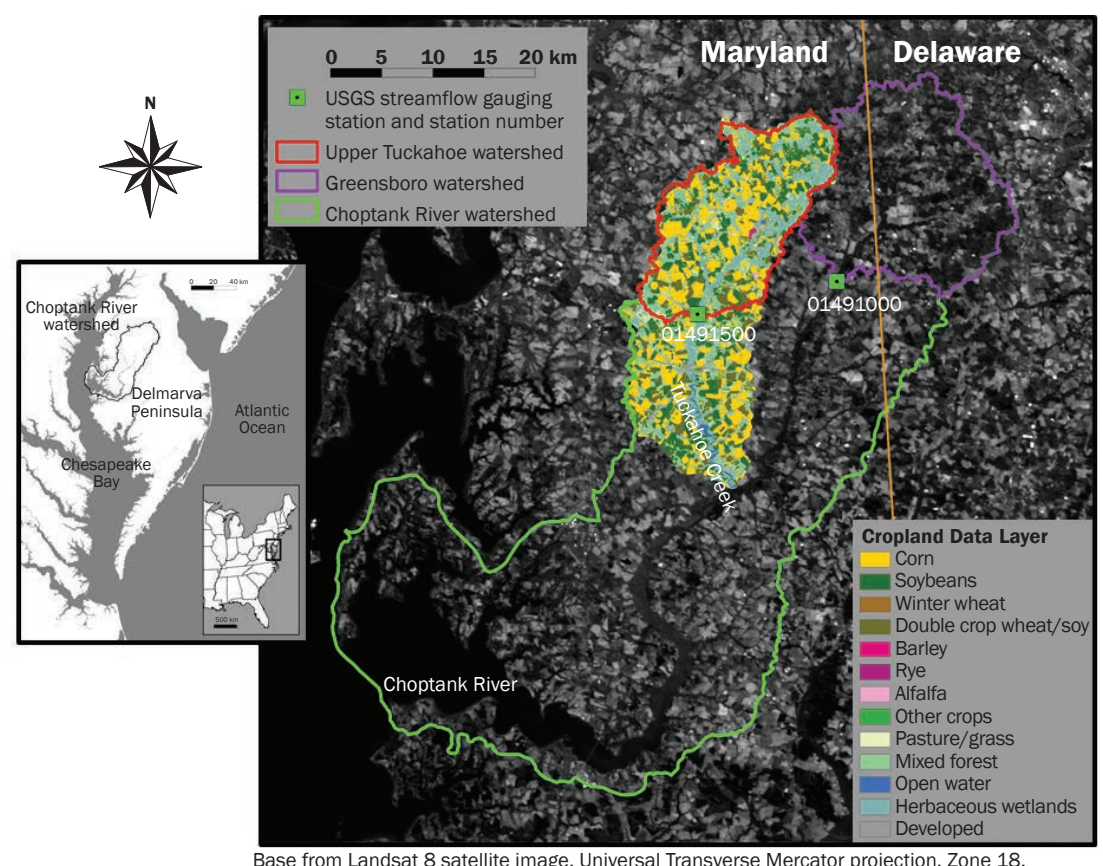

North American Datum 1983

simulates eight major components related to transport of agricultural contaminants: hydrology, weather, sedimentation, soil temperature, crop growth, nutrients, pesticides, and agricultural management (Neitsch et al. 2002). Major hydrologic processes that can be simulated by the model include evapotranspiration, surface runoff, percolation, shallow and deep aquifer flows, and channel routing (Arnold et al. 1998). Streamflow in the main channel is determined by three sources: surface runoff, lateral flow, and base flow from shallow aquifers.

Yeo et al. (2014) adapted the SWAT model for simulation of cover crop growth by using the remote sensing analysis and on-farm sampling data provided in Hively et al. (2009) to develop species-specific relationships between accumulated growing degrees and cover crop biomass, which provided the basis for SWAT modeling of cover crop performance in the Choptank River watershed (Lee et al. 2016, 2017b, 2017c, 2018b). These cover crop growth parameters provided the basis for modeling the impact of cover crops on $\mathrm{NO}_{3}{ }^{-}$ leaching from cropland in the present study.

Research by the Choptank River CEAP has documented the impacts of WCC on nutrient reductions using a combination of remote sensing, on-farm sampling, SWAT modeling, and analysis of MACS enrollment records. Study findings document that $\mathrm{NO}_{3}^{-}$reduction efficiency of WCC varied by agronomic implementation method, watershed characteristics, and crop rotation (Hively et al. 2009; Yeo et al. 2014; Lee et al. 2016), and that early-planted WCC were more effective in reducing $\mathrm{NO}_{3}^{-}$loads than late-planted WCC due to warmer conditions and longer growing periods (Hively et al. 2009; Yeo et al. 2014; Lee et al. 2016). In addition, rye cover crops were found to outperform barley and wheat cover crops, most likely due to their increased cold tolerance, hardiness, and more rapid root system development during the early winter (Hively et al. 2009; Staver et al. 1989; Prabhakara et al. 2015). Additionally, the Choptank CEAP team developed techniques to support the analysis of multiyear trends in wintertime ground cover by combining satellite vegetation indices with knowledge of summer crop type derived from the Cropland Data Layer (CDL) (Hively et al. 2015).

The focus of this paper was to explore the novel combination of multiyear cost-share program enrollment data, remote sensing of wintertime vegetation, and SWAT model 
simulations to describe how trends in WCC implementation appear to have impacted nutrient loading in an agricultural watershed (Tuckahoe Creek) adjacent to a highly sensitive estuarine ecosystem (the Chesapeake Bay). This combination of data sources supports evaluation of WCC effects on $\mathrm{NO}_{3}^{-}$ leaching in the context of landscape, climate, and conservation.

\section{Materials and Methods}

Study Site. The area of interest for this study was the Tuckahoe Creek watershed, located in the headwaters of the Choptank River (figure 1). The Tuckahoe Creek watershed $\left(400 \mathrm{~km}^{2}\right)$ is defined by the eight-digit hydrological unit code (HUC8) \#02130405, which is the area for which MACS cover crop implementation records were available. Land use is $47 \%$ agricultural cropland, $41 \%$ forest, and 8\% low intensity urban development. Major soil types in the Tuckahoe Creek watershed are typically Othello soil series (fine-silty, mixed, active, mesic Typic Endoaquults) and Mattapex series (fine-silty, mixed, active mesic Aquic Hapludults), with slopes ranging from $2 \%$ to $5 \%$, underlain by the Columbia aquifer (McCarty et al. 2008). Approximately $44 \%$ of the agricultural soils are poorly drained (Soil Survey Geographic Database [SSURGO] drainage classes $\mathrm{C}$ and D), and much of the agricultural land is ditch drained. The climate in the region is humid with an annual average rainfall of $110 \mathrm{~cm}$. Average monthly temperatures range from $2{ }^{\circ} \mathrm{C}$ in January/February to $25^{\circ} \mathrm{C}$ in July/ August, with a yearly average of $12.8^{\circ} \mathrm{C}$.

The upper $225 \mathrm{~km}^{2}$ of the Tuckahoe Creek watershed ("Upper Tuckahoe") drain through a streamflow gauging station maintained by the US Geological Survey (USGS station \#01491500), and the flow is nontidal above the gauging station. The Upper Tuckahoe watershed has previously been the subject of SWAT modeling, with calibration/validation provided by stream gauge and water quality sampling data records (Lee et al. 2016, 2017b, 2017c). The Upper Tuckahoe watershed is composed of $54 \%$ agriculture, 33\% forested, $8 \%$ pasture, and 4\% developed area (Lee et al. 2016). Previous CEAP studies have contrasted the Upper Tuckahoe watershed with the adjacent Greensboro watershed, a similarly sized watershed located at the headwaters of the Choptank River (figure 1) with higher amounts of forested wetlands, poorly drained soils, and ditch drainage of agricultural areas. These studies (Denver et al. 2014; Lee et al. 2016; McCarty et al. 2014; Sharifi et al. 2016) highlighted the importance of hydrogeomorphology on nutrient transport, with the Greensboro demonstrating quick flow of $\mathrm{NO}_{3}{ }^{-}$through ditch drainage, accompanied by denitrification of anoxic groundwater. The Upper Tuckahoe watershed, in contrast, had reduced overland flow, with comparatively high concentrations of $\mathrm{NO}_{3}^{-}$in oxic groundwaters (Denver et al. 2014). Stream incision in the Upper Tuckahoe watershed has led to the occurrence of narrow riparian forested buffers along the stream corridors. Transport times of groundwater and $\mathrm{NO}_{3}^{-}$ from field to stream average 10 to 15 years (Sanford et al. 2013).

Cover Crop Implementation. Enrollment records for the MACS WCC program were obtained from the Maryland Department of Agriculture. These records, documenting annual enrollment from 2008 through 2017, contained agronomic information for every field within the Tuckahoe Creek watershed that was enrolled in the MACS cover crop program $(n=4,447)$, including planting date, cover crop species, area planted, and previous summer crop type. Planting date was subsequently categorized according to cutoff dates used by the cover crop cost-share program, defined as early (planted before October 1), standard (planted October 1 to October 14), and late (planted October 15 to mid-November).

The pertinent cover crop program enrollment data were identified by HUC8 watershed code, locating them within the Tuckahoe Creek watershed (HUC \#02130405). Cover crop enrollment data were available only for Maryland, and therefore the Greensboro watershed, which spans Maryland and Delaware, was excluded from the current analysis. It should be noted that the Tuckahoe Creek HUC8 watershed (400 $\mathrm{km}^{2}$ ) is larger than the SWAT modeling extent for the Upper Tuckahoe Creek (220 $\mathrm{km}^{2}$ ). For the purposes of this analysis, it was assumed that the distribution of cover crops was similar for the Tuckahoe Creek and Upper Tuckahoe watersheds.

Wintertime Ground Cover Analysis: 2008 to 2017. Satellite remote sensing analysis of wintertime ground cover was achieved using a toolkit developed by the Choptank CEAP team for use in ArcGIS, described in Hively et al. (2015). The toolkit combines satellite imagery, mapped CDL summer crop type, and watershed boundaries to calculate the distribution of vegetation abundance by summer crop type for the area of interest.

Wintertime Landsat surface reflectance imagery from Path 14 Row 33 were obtained using Google Earth Engine (Google Inc., Mountain View, California) (Gorelick et al. 2017). Within Google Earth Engine, Landsat imagery was masked to exclude snow and clouds using the Landsat Quality Assessment (QA) bands. The masked Landsat imagery was subsequently converted to the Normalized Difference Vegetation Index (NDVI):

$\mathrm{NDVI}=(\mathrm{NIR}-\mathrm{R}) /(\mathrm{NIR}+\mathrm{R})$,

using Landsat bands for near infrared reflectance (NIR) and red reflectance (R). The NDVI (Tucker 1979) is a commonly used index that correlates well with the leaf area index of green vegetation. For Maryland WCC specifically, NDVI has been found to perform as well as or better than nine other vegetation indices for measuring vegetation biomass and percentage ground cover (Prabhakara et al. 2015).

For each year, all available Landsat NDVI surface reflectance imagery acquired between November 15 and March 1 were layer stacked and composited to select the maximum NDVI value for each pixel. This amounted to six to seven wintertime images per year, spaced 16 days apart, with cloudy pixels removed from the analysis. The result was one composite maximum NDVI Landsat image per year (2008 to 2017) that was subsequently used for wintertime greenness analysis after being exported from Google Earth Engine.

Using the ArcGIS-based ground cover calculation tool developed by the Choptank CEAP (Hively et al. 2015), the composite maximum NDVI image for each year was segmented into four vegetation classes representing minimal, low, medium, and high levels of wintertime vegetation, using NDVI threshold values of minimal biomass ( 0.10 to 0.29 ), low biomass (0.29 to 0.40), medium biomass ( 0.40 to 0.53$)$, and high biomass (0.53 to 0.99$)$. The threshold values of 0.29 , 0.40 , and 0.53 correspond to approximately 100,200 , and $500 \mathrm{~kg} \mathrm{ha}^{-1}$ biomass, respectively (Prabhakara et al. 2015), which would equate to approximately 2,4 , and $10 \mathrm{~kg} \mathrm{ha}^{-1}$ of aboveground $\mathrm{N}$ content, respectively, if a $2 \%$ tissue $\mathrm{N}$ content is assumed for small 
grain WCC in the vegetative growth stage (Hively et al. 2009).

Maps of CDL summer crop type for the Tuckahoe Creek watershed were obtained from CropScape (USDA NASS 2019). Each year's CDL information was overlaid on the subsequent wintertime NDVI imagery to calculate the percentage of each summer crop type falling into each wintertime vegetation class (e.g., summer 2014 CDL was combined with winter 2014 to 2015 satellite imagery).

Satellite-based wintertime ground cover analysis was performed for each year for which CDL crop type maps were available (2008 to 2017) using the CEAP-developed ArcGIS ground cover calculation tool (Hively et al. 2015). Inputs included the composite maximum NDVI Landsat 8 imagery compiled between November 15 and March 1 (e.g., year "2008" composites imagery from November 15, 2008, to March 1, 2009, yielding the highest NDVI value per pixel observed during this date range) and summer crop type from the CDL (e.g., summer 2008 CDL was paired with winter 2008 to 2009 maximum NDVI imagery). We also tested imagery composites derived using a narrower date range (December to January), and found no substantial difference in results from the November 15 to March 1 Landsat imagery composite. For further detail on the ArcGIS toolkit and the method used to calculate wintertime vegetation cover, refer to Hively et al. (2015).

The sum of accumulated daily growing degrees, base $4^{\circ} \mathrm{C}$ (GDD4), was calculated from September 1 of each year until March 31 , to gain insight into how much the variation in wintertime growing conditions affected the satellite vegetation analysis. Daily GDD4 was calculated as equation 2:

GDD4 $=\left[\left(\mathrm{T}_{\max }+\mathrm{T}_{\min }\right) / 2\right]-4$,

where $T_{\max }$ and $T_{\text {min }}$ were the maximum and minimum recorded daily air temperatures $\left({ }^{\circ} \mathrm{C}\right)$, respectively. Days with negative values were set to equal zero before summation. Weather data used to calculate GDD4 were obtained from a weather station located at the University of Maryland Wye Research Station (3854"31' N; 7608'38' W; University of Maryland 2018).

Wintertime Ground Cover Analysis: 1984 to 2017. To expand the vegetation analysis beyond the period of record for CDL availability (2008 to present), long-term cropland hectares were determined by layer stacking the 10 years of annual CDL and identifying pixels that were cropland $>80 \%$ of the time. The resulting area (18,700 ha) occupied $46 \%$ of the Tuckahoe Creek watershed, and for the purposes of this analysis was assumed to be stable as cropland over time. This longterm cropland mask was combined with annual wintertime (November 15 to March 1) composite maximum NDVI Landsat imagery for the time period of 1984 to 2017, and the ground cover toolkit was used to calculate the distributions of wintertime vegetative ground cover on cropland. For this long-term analysis, annual wintertime maximum NDVI imagery composites were calculated using a combination of Landsat 5 $(\mathrm{NIR}=$ Band 4 , Red $=$ Band 3$)$, Landsat 7 $(\mathrm{NIR}=$ Band $4, \mathrm{Red}=$ Band 3$)$, and Landsat $8(\mathrm{NIR}=$ Band 5 , Red $=$ Band 4$)$.

SWAT Modeling. As part of CEAP research in the Choptank River watershed, SWAT was calibrated to streamflow and nutrient loading from the Upper Tuckahoe and Greensboro watersheds (figure 1) to examine the water quality effects of WCC on reducing $\mathrm{N}$ loading based on (1) cover crop species and planting date (Yeo et al.2014), (2) hydrogeomorphological differences between the watersheds (Lee et al. 2016), and (3) effects of future climate conditions (Lee et al. $2017 b, 2017$ c). For the current study, we used the calibrated SWAT model for the Upper Tuckahoe watershed to assess the impacts of WCC on the leaching of $\mathrm{NO}_{3}^{-}$from agricultural lands from 2008 to 2017, the period for which WCC MACS enrollment data and CDL land use data were available, and similar to the period for which the Upper Tuckahoe SWAT model had previously been calibrated (2001 to 2008) and validated (2009 to 2014) (Lee et al. 2018b). Within the SWAT model, summer crop rotations were parameterized using a multiyear sequence of CDL information (Lee et al. 2016) and management details provided in table 1 . The model calibration and validation were conducted under no-winter-cover-crop conditions ("No WCC scenario," Lee et al. [2016]). Overall, model Nash-Sutcliffe efficiency coefficient (NSE) performance measures were "good" (e.g., 0.65 to 0.75$)$ or "very good" $(>0.75)$ criteria for streamflow and at least "satisfactory" ( 0.5 to 0.65 ) for $\mathrm{NO}_{3}^{-}$loads (Lee et al. 2018b). The SWAT simulations used historically accurate precipitation and temperature data from the University of Maryland Wye
Research Center (located adjacent to the Choptank River watershed) to drive the model calculations.

Nine WCC scenarios were developed to represent changes in $\mathrm{NO}_{3}^{-}$loading resulting from WCC implementation, including all combinations of three small grain WCC species (wheat, rye, and barley) and three planting dates (October 3, October 17, and November 2) chosen to simulate the early, standard, and late planting date categories established by the MACS WCC cost-share program. WCC growth parameters were directly adopted from Yeo et al. (2014), simulating WCC growth and biomass production based on species-specific response to accumulated growing degrees observed in the winter of 2005 to 2006 (Hively et al. 2009). WCC performance was evaluated based on SWAT model outputs summarized from September 1 through March 31 (hereafter referred to as the "winter period"). Simulated $\mathrm{NO}_{3}^{-}$leaching only from croplands was used to quantify WCC performance.

\section{Results and Discussion}

Cover Crop Implementation. From 2008 through 2017, 91,790 ha of WCC were planted in the Tuckahoe Creek watershed (table 2$)-33 \%$ in the early planting category (prior to October 1), 28\% in the standard planting category (October 1 to 14), and $39 \%$ in the late planting category (October 15 to mid-November). The large majority of planted cover crop was wheat $(68.1 \%)$, followed by barley $(16.1 \%)$, rye $(7.2 \%)$, forage radish $(4.4 \%)$, triticale (Triticale hexaploide Lart.; 1.7\%), and canola (1.0\%), as well as clover (Trifolium spp.)/wheat mix, legume/ cereal mix, ryegrass, and spring oats (Avena sativa) (each $<1 \%$ of total cover crop area). Planting dates for wheat were generally late (51\%), whereas planting dates for barley tended to be early (50\%), and planting dates were more evenly distributed for rye $(39 \%$ early, 35\% late). Overall, the largest proportion of WCC, when segmented by species and planting date category, was late-planted wheat $(34.7 \%$ of all WCC).

The area of summer row crops planted within the Tuckahoe Creek watershed, calculated from the CDL, varied somewhat from 2008 to 2017, ranging from 7,520 ha to 11,830 ha of corn and from 10,580 ha to 15,350 ha of soybean (table 3 , figure 2 ). The apparent area planted to corn decreased rapidly from $2011(11,540 \mathrm{ha})$ to 2012 
Table 1

Management schedules for baseline and winter cover crop SWAT model scenarios (adapted from Lee et al. 2016).

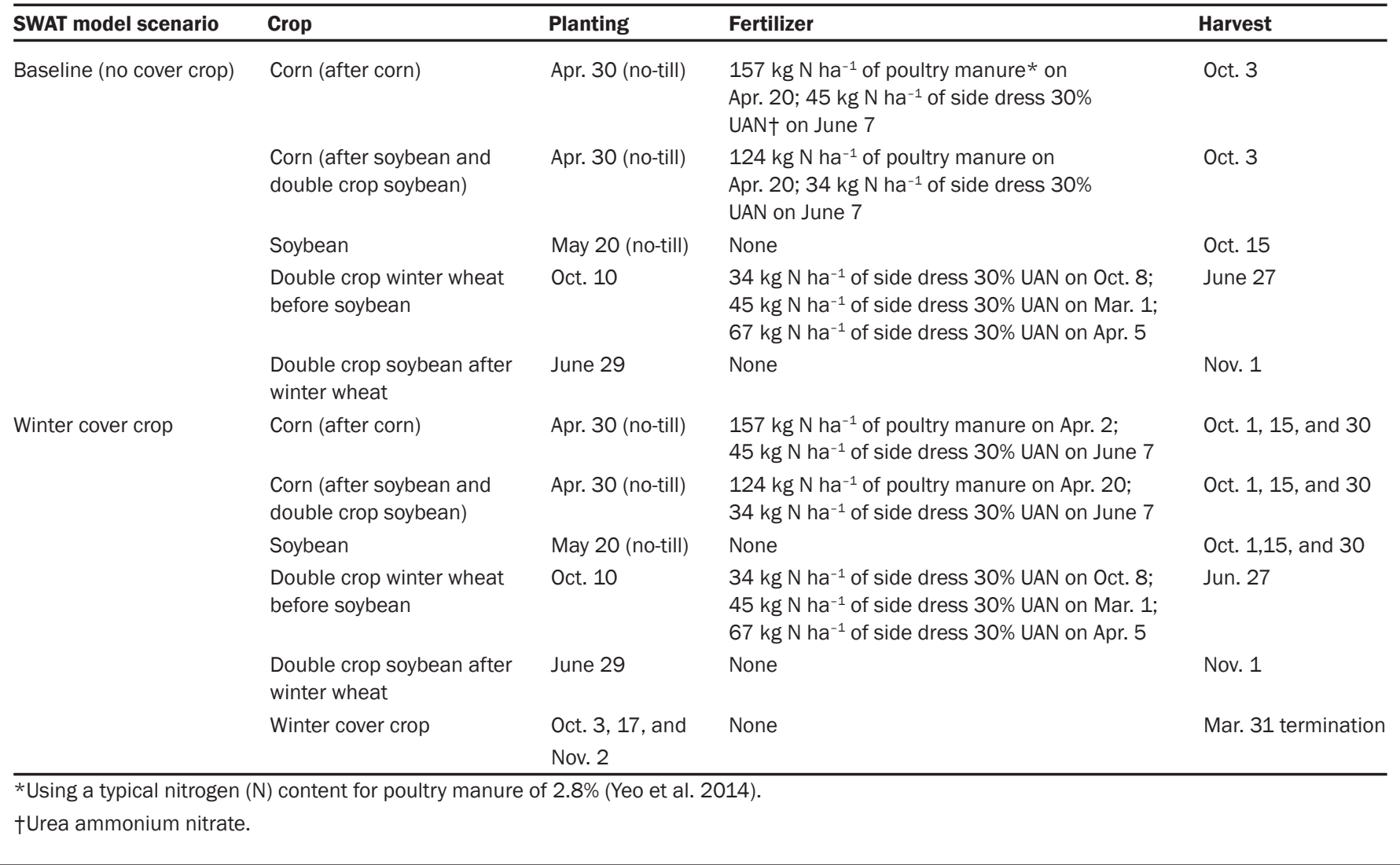

\section{Table 2}

Enrollment in the Maryland winter cover crop cost-share program, Tuckahoe Creek watershed, 2008 to 2017. Planting date categories are defined as early (prior to October 1), standard (October 1 to 14 ), and late (October 15 to mid-November).

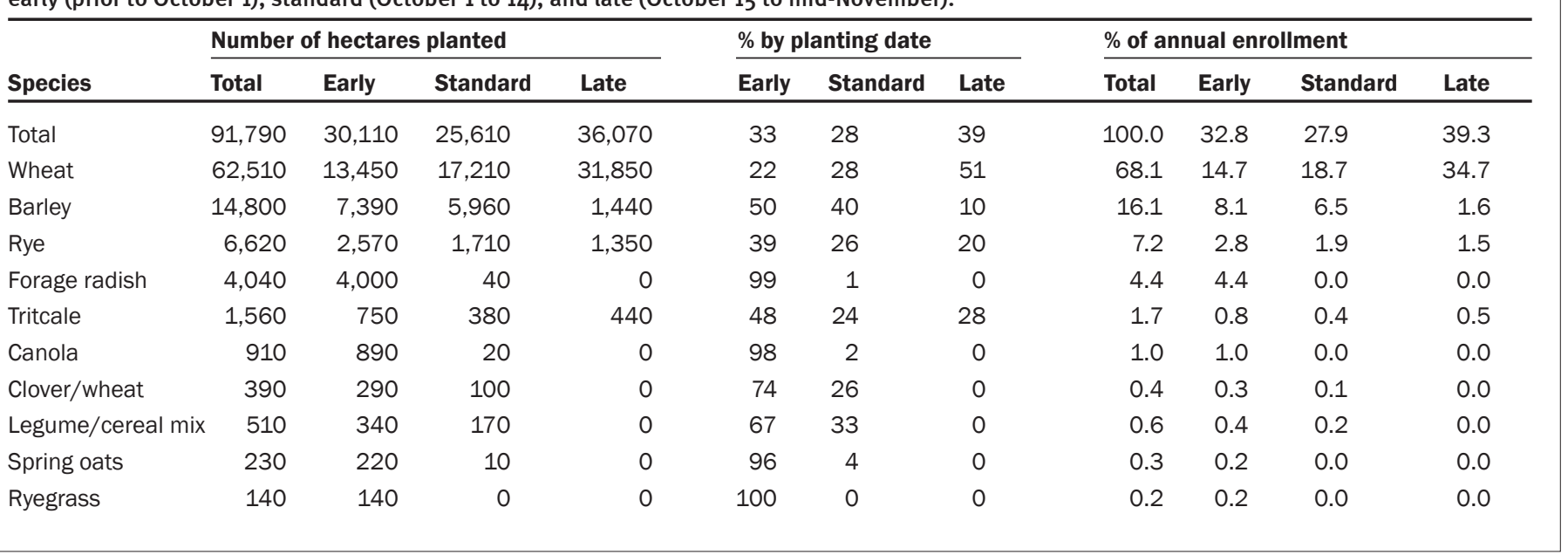

(8,260 ha), rising again in 2017. However, similar changes in corn area were not seen in USDA National Agricultural Statistics Service (NASS) county-level statistics, perhaps calling into question the consistency of the CDL data product. Soybean area was more stable, apart from a high value in 2008 (table 3, figure 2). Overall, the percentage of the watershed occupied by row crops varied from a low of $50 \%$ in 2012 to 2013 to a high of $68 \%$ in 2008 (table 3 ).
The area of WCC planted within the Tuckahoe Creek watershed increased steadily from 2008 (4,580 ha) to 2016 (13,390 ha), with most cover crops planted following corn $(60 \%)$ and soybeans (26\%) (table 3). These data were derived directly from MACS cost- 


\section{Table 3}

Annual area of summer crops determined using Cropland Data Layer, annual percentage of watershed area occupied by summer row crops, annual enrollment in the Maryland cover crop cost-share program by previous summer crop type, and annual percentage of summer crop fields enrolled in the Maryland cover crop cost-share program, Tuckahoe Creek watershed, 2008 to 2017.

\begin{tabular}{|c|c|c|c|c|c|c|c|c|c|c|c|}
\hline $\begin{array}{l}\text { Crop } \\
\text { type }\end{array}$ & 2008 & 2009 & 2010 & 2011 & 2012 & 2013 & 2014 & 2015 & 2016 & 2017 & $\begin{array}{l}2008 \text { to } \\
2017\end{array}$ \\
\hline \multicolumn{12}{|c|}{ Area of summer row crops (ha) within the Tuckahoe Creek watershed, from annual Cropland Data Layer } \\
\hline Corn & 11,680 & 11,830 & 11,320 & 11,540 & 8,260 & 8,080 & 7,900 & 7,520 & 8,460 & 11,650 & 98,250 \\
\hline $\begin{array}{l}\text { Full season } \\
\text { soybean }\end{array}$ & 6,130 & 5,080 & 7,590 & 4,570 & 3,080 & 2,730 & 4,030 & 5,600 & 4,320 & 8,010 & 51,150 \\
\hline $\begin{array}{l}\text { Double crop } \\
\text { soybean }\end{array}$ & 9,220 & 7,000 & 4,610 & 6,010 & 8,510 & 9,140 & 8,750 & 7,820 & 8,080 & 4,110 & 73,240 \\
\hline $\begin{array}{l}\text { All soybean } \\
\text { crops }\end{array}$ & 15,350 & 12,080 & 12,200 & 10,580 & 11,590 & 11,870 & 12,780 & 13,420 & 12,400 & 12,120 & 124,390 \\
\hline $\begin{array}{l}\text { All corn + } \\
\text { soybean }\end{array}$ & 27,030 & 23,910 & 23,520 & 22,120 & 19,850 & 19,950 & 20,680 & 20,940 & 20,860 & 23,770 & 222,640 \\
\hline \multicolumn{12}{|c|}{ Percentage of total Tuckahoe Creek watershed area $(39,941$ ha) occupied by summer crops } \\
\hline Corn & 29 & 30 & 28 & 29 & 21 & 20 & 20 & 19 & 21 & 29 & 25 \\
\hline $\begin{array}{l}\text { Full season } \\
\text { soybean }\end{array}$ & 15 & 13 & 19 & 11 & 8 & 7 & 10 & 14 & 11 & 20 & 13 \\
\hline $\begin{array}{l}\text { Double crop } \\
\text { soybean }\end{array}$ & 23 & 18 & 12 & 15 & 21 & 23 & 22 & 20 & 20 & 10 & 18 \\
\hline $\begin{array}{l}\text { All soybean } \\
\text { crops }\end{array}$ & 38 & 30 & 31 & 26 & 29 & 30 & 32 & 34 & 31 & 30 & 31 \\
\hline $\begin{array}{l}\text { All corn + } \\
\text { soybean }\end{array}$ & 68 & 60 & 59 & 55 & 50 & 50 & 52 & 52 & 52 & 59 & 56 \\
\hline \multicolumn{12}{|c|}{ Area of winter cover crop enrollment (ha), by previous summer crop type, from MDA enrollment records } \\
\hline Corn & 3,170 & 3,230 & 5,410 & 6,710 & 7,040 & 6,390 & 6,660 & 6,310 & 7,570 & 6,240 & 58,730 \\
\hline Soybean & 1,350 & 840 & 2,540 & 2,860 & 2,880 & 2,950 & 3,960 & 4,670 & 5,770 & 4,030 & 31,830 \\
\hline Vegetables & 60 & 150 & 70 & 70 & 110 & 110 & 50 & 60 & 40 & 130 & 830 \\
\hline Sorghum & - & - & 23 & 60 & 90 & 20 & 20 & 40 & 20 & 130 & 390 \\
\hline All crops & 4,580 & 4,220 & 8,040 & 9,700 & 10,110 & 9,460 & 10,700 & 11,090 & 13,390 & 10,510 & 91,790 \\
\hline \multicolumn{12}{|c|}{ Percentage of summer crop area enrolled in winter cover crop cost-share program, by crop type } \\
\hline Corn & 27 & 27 & 48 & 58 & 85 & 79 & 84 & 84 & 89 & 54 & 60 \\
\hline Soybean & 9 & 7 & 21 & 27 & 25 & 25 & 31 & 35 & 46 & 33 & 26 \\
\hline $\begin{array}{l}\text { All corn + } \\
\text { soybean }\end{array}$ & 17 & 17 & 34 & 43 & 50 & 47 & 51 & 52 & 64 & 43 & 41 \\
\hline
\end{tabular}

share enrollment records and were judged to be accurate. The area of cover crops planted following corn more than doubled between 2009 (3,230 ha) and 2011 (6,710 ha), and then held consistent through 2017 (table 3, figure 2). The rise in cover crop adoption corresponded to increased outreach and funding provided by the MACS program.

The percentage of corn fields enrolled in the WCC program more than doubled over the study period, increasing from $27 \%$ in 2008 to $54 \%$ in 2017 , with a maximum of $89 \%$ of corn fields cover cropped in 2016 (table 3, figure 2). The apparent decrease from 2016 to 2017 resulted from a change in MACS regulations to no longer provide cost-share for WCC that are grown for harvest as commodity cover crops. The percentage of soybean fields enrolled in the WCC program increased from $9 \%$ to $33 \%$ between 2008 and 2017, with the maximum of $46 \%$ occurring in 2016 (table 3, figure 2 ). The large majority of the postsoybean WCC were planted following full season soybean, with zero enrollment reported following double crop soybeans prior to 2015 . In this region, the order of harvest is typically corn followed by soybean followed by double crop soybean, such that cover crop implementation is most prevalent following corn due to the greater amount of warm fall weather available for cover crop planting and growth. Overall, implementation of cover crops increased from $17 \%$ of row crop fields in 2008 to $43 \%$ of row crop fields in 2017 (64\% in 2016), with a rapid rise in cover crop adoption observed beginning in 2010 (table 3 , figure 2).

Wintertime Ground Cover Analysis: 2008 to 2017. Satellite-based wintertime ground cover analysis was performed for each year for which CDL crop type maps were available (2008 to 2017) using the CEAPdeveloped ArcGIS ground cover calculation tool (Hively et al. 2015). Tabular results of the ground cover analysis are reported in table 4. Raster map output is shown in figure 3.

Within each year there were clear differences in wintertime vegetation associated with each summer crop type, with perennial crops such as alfalfa (Medicago sativa) and hay exhibiting high levels of vegetation, followed in decreasing order by corn, full season soybean, and double-cropped soybean (table 


\section{Figure 2}

Annual area of summer row crops determined using Cropland Data Layer (CDL), annual area of planted cover crops, and percentage of summer row crop fields enrolled in the Maryland cover crop cost-share program, Tuckahoe Creek watershed, 2008 to 2017.

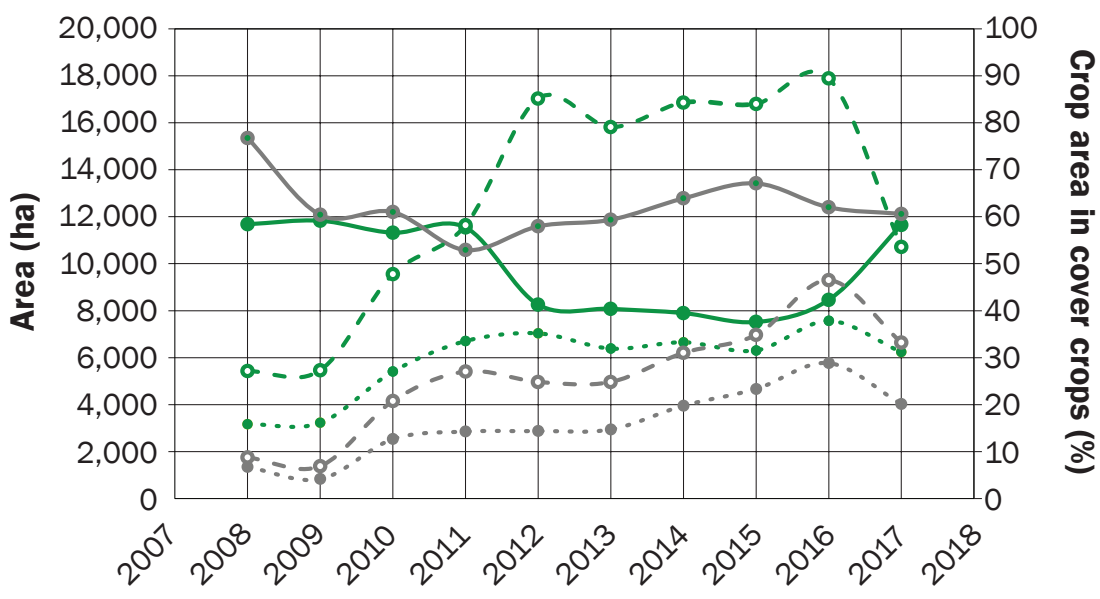

Year

\section{Legend}

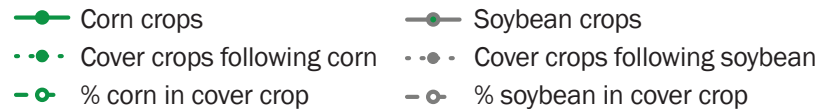

4, figure 4). This observation was in accordance with the perennial nature of alfalfa and hay crops, and the frequency of cover crop occurrence following each type of summer row crop (table 3). Note that there appears to be a change in the CDL classification in 2010 that led to an anomalous separation of full season and double crop soybeans for that year (figure 4).

Trends in wintertime vegetative ground cover, as determined using satellite imagery analysis, were expected to increase over time, in parallel with increasing cover crop implementation. However, within the 10-year data set overlapping with the CDL period of record, any such trends were obscured by variability in wintertime climate. While a general nonsignificant trend was observed toward increased occurrence of nonminimal vegetative cover (slope $=1.7, R^{2}=0.28$ ), the year-to-year variation in climate and agronomy had a strong influence on the prevalence of wintertime vegetation, such that years with a late harvest of summer crops and poor weather for cover crop establishment and growth exhibited minimal vegetation across the landscape. In contrast, years with favorable cover crop planting conditions and warm winter conditions promoted increased cover crop growth, along with increased levels of green vegetation throughout the landscape.

There appeared to be covariation between wintertime growing conditions (GDD4 accumulated from November 15 through March 1) and prevalence of nonminimal biomass (figure 5). Years with warm weather and abundant rainfall (2011, 2015 to 2017; figure 5, table 5) exhibited higher levels of vegetation, while years with colder winter temperatures (2012 to 2014; figure 5, table $5)$ and drought during the cover crop planting season (2013) exhibited reduced levels of wintertime vegetation. However, 2009 and 2010, the years with lowest implementation of cover crops, also exhibited the lowest wintertime vegetation, apart from the cold drought year of 2013.

Wintertime Ground Cover Analysis: 1984 to 2017. When vegetation analysis was expanded to a longer time period (1984 to 2017) using the calculated long-term cropland mask, results (figure 6a) showed increasing levels of medium-high vegetation (NDVI > 0.4) over time, with interannual variation strongly correlated to wintertime growing temperatures (GDD4 accumulated between November 15 and March 1), and long-term trends associated with implementation of WCC.
Three time periods were identified, representing near zero cover crop implementation (1984 to $1997 ; 128$ to 1,330 ha of WCC), moderate cover crop implementation (1998 to $2009 ; 1,156$ to 13,019 ha of WCC), and substantial cover crop implementation (2010 to $2017 ; 10,420$ to 33,080 ha of WCC). Each of these periods demonstrated a different relationship between winter temperatures (GDD4) and wintertime vegetation, with increased vegetation associated with periods of higher cover crop adoption (figure 6b).

Analysis of variance (ANOVA) was performed using the following model:

Vegetative ground cover $=$ GDD 4

+ time period $+\varepsilon$,

where "vegetative ground cover" represents percentage of cropland exhibiting medium-high levels of wintertime vegetation, "GDD4" represents accumulated growing degrees (base $4^{\circ} \mathrm{C}$ ) within each winter season, "time period" is a categorical variable distinguishing the three implementation time periods (1984 to 1997; 1998 to $2009 ; 2010$ to 2017 ), and " $\varepsilon$ " represents model error. Results showed a strong correlation between vegetative ground cover and GDD4, a primary driver of wintertime greenness ( $p$-value $<0.000$, explaining 32\% of observed variation), and a strong secondary correlation with the time periods of increasing WCC implementation ( $p$-value $<0.000$, explaining $37 \%$ of observed variation), with an overall model goodness of fit $\left(R^{2}\right)$ of 0.69 . Thus, using the long-term analysis, the effect of WCC implementation on wintertime vegetation abundance was clearly detected (measured using the time period variable), despite the strong influence of interannual variability in wintertime growing conditions (measured using GDD4).

SWAT Modeling. SWAT model results using the 10-year average (2008 to 2017) of simulated leaching from croplands (corn and soybean) during the winter period (September 1 to March 31) indicated $\mathrm{NO}_{3}{ }^{-}$ leaching of $26.2 \mathrm{~kg} \mathrm{~N} \mathrm{ha}^{-1} \mathrm{y}^{-1}$ under baseline (no cover crop) conditions (table 5). Annual baseline loads ranged from 19.7 to $35.8 \mathrm{~kg}$ $\mathrm{N}$ ha ${ }^{-1}$, with variation depending strongly $\left(R^{2}=0.73\right)$ on observed precipitation, which strongly affected leaching processes, and a nonsignificant relationship $\left(R^{2}=0.09\right)$ between $\mathrm{NO}_{3}^{-}$leaching and accumulated wintertime growing degrees in the absence 


\section{Table 4}

Percentage of each summer row crop type falling within subsequent wintertime vegetative abundance classes (minimal, low, medium, and high), determined through satellite imagery analysis. Vegetation thresholds were established using the Normalized Difference Vegetation Index (NDVI), including fields with minimal vegetation ( $0.10<\mathrm{NDVI}<0.29$, includes bare soil and nonphotosynthetic crop residue), and fields with low ( $0.29<\mathrm{NDVI}$ $<0.40)$, medium ( $0.40<\mathrm{NDVI}<0.53)$, and high ( $0.53<\mathrm{NDVI}<0.99)$ levels of vegetation. The threshold values of 0.29 , 0.40 , and 0.53 correspond to approximately 100, 200, and $500 \mathrm{~kg} \mathrm{ha}^{-1}$ of aboveground biomass (Prabhakara et al. 2015). The previous summer's row crop type was determined using the annual Cropland Data Layer (https://data.nal.usda.gov/dataset/cropscape-cropland-data-layer).

\begin{tabular}{|c|c|c|c|c|c|c|c|c|c|c|c|}
\hline $\begin{array}{l}\text { Row crop } \\
\text { type }\end{array}$ & Class & 2008 & 2009 & 2010 & 2011 & 2012 & 2013 & 2014 & 2015 & 2016 & 2017 \\
\hline \multirow[t]{4}{*}{ Corn } & Minimal (\%) & 20 & 22 & 14 & 3 & 6 & 22 & 18 & 2 & 5 & 11 \\
\hline & Low (\%) & 25 & 31 & 22 & 7 & 10 & 38 & 27 & 6 & 17 & 19 \\
\hline & Medium (\%) & 31 & 30 & 33 & 22 & 29 & 26 & 30 & 16 & 34 & 27 \\
\hline & High (\%) & 24 & 17 & 31 & 69 & 54 & 14 & 26 & 76 & 44 & 43 \\
\hline \multirow{4}{*}{$\begin{array}{l}\text { Full season } \\
\text { soybeans }\end{array}$} & Minimal (\%) & 21 & 20 & 43 & 10 & 12 & 22 & 13 & 4 & 6 & 42 \\
\hline & Low (\%) & 27 & 31 & 32 & 18 & 35 & 37 & 31 & 12 & 17 & 34 \\
\hline & Medium (\%) & 34 & 32 & 18 & 42 & 40 & 30 & 37 & 25 & 35 & 15 \\
\hline & High (\%) & 18 & 17 & 7 & 30 & 13 & 11 & 20 & 60 & 42 & 9 \\
\hline \multirow{4}{*}{$\begin{array}{l}\text { Double crop } \\
\text { soybeans }\end{array}$} & Minimal (\%) & 52 & 53 & 20 & 31 & 43 & 51 & 38 & 13 & 12 & 20 \\
\hline & Low (\%) & 27 & 26 & 32 & 31 & 32 & 29 & 32 & 20 & 28 & 31 \\
\hline & Medium (\%) & 16 & 14 & 35 & 27 & 20 & 15 & 19 & 28 & 34 & 30 \\
\hline & High (\%) & 6 & 7 & 13 & 11 & 5 & 5 & 11 & 40 & 26 & 19 \\
\hline \multirow[t]{4}{*}{ All row crops } & Minimal (\%) & 30 & 30 & 21 & 12 & 22 & 34 & 24 & 6 & 7 & 19 \\
\hline & Low (\%) & 26 & 30 & 27 & 15 & 23 & 34 & 30 & 12 & 21 & 25 \\
\hline & Medium (\%) & 27 & 26 & 31 & 27 & 27 & 22 & 27 & 23 & 34 & 26 \\
\hline & High (\%) & 17 & 14 & 21 & 46 & 28 & 10 & 19 & 59 & 37 & 29 \\
\hline \multirow[t]{4}{*}{ Hay } & Minimal (\%) & 14 & 1 & 3 & 1 & 2 & 3 & 1 & 1 & 0 & 2 \\
\hline & Low (\%) & 26 & 7 & 15 & 5 & 11 & 8 & 5 & 2 & 2 & 7 \\
\hline & Medium (\%) & 33 & 21 & 41 & 33 & 42 & 33 & 20 & 14 & 17 & 22 \\
\hline & High (\%) & 28 & 71 & 41 & 60 & 45 & 56 & 75 & 83 & 81 & 69 \\
\hline \multirow[t]{4}{*}{ Alfalfa } & Minimal (\%) & 13 & 1 & 1 & 0 & 0 & 8 & 3 & 3 & 0 & 1 \\
\hline & Low (\%) & 21 & 3 & 3 & 1 & 6 & 14 & 4 & 3 & 2 & 3 \\
\hline & Medium (\%) & 22 & 9 & 16 & 11 & 13 & 18 & 12 & 3 & 12 & 14 \\
\hline & High (\%) & 44 & 88 & 80 & 87 & 80 & 60 & 81 & 91 & 86 & 82 \\
\hline
\end{tabular}

of WCC. The years with highest loads $(2009$, 2012, and 2013) were also the years with highest observed rainfall (table 5).

Compared to the baseline scenario, simulated WCC implementation substantially reduced $\mathrm{NO}_{3}^{-}$leaching by $25 \%$ to $96 \%$ depending on annual climate and WCC scenario (table 6), with 10-year average load reductions of $40 \%$ to $85 \%$ depending on WCC species and planting date. These scenarios assumed that $100 \%$ of cropland was planted to each individual WCC type (species and planting date combination). The percentage reduction in $\mathrm{NO}_{3}^{-}$leaching was not strongly correlated with the magnitude of baseline load, but rather seemed to reflect the favorability of climate for WCC growth, relative to the influence of observed precipitation on leaching processes. Cover crop performance (table 6) was strongly correlated to accumulated wintertime growing degrees (table 5) for late-planted WCC $\left(R^{2}=0.65\right.$ to 0.74 for the various species) but was not as well correlated for early-planted WCC $\left(R^{2}=\right.$ 0.07 to 0.26 ), likely because the cover crops achieved the bulk of their $\mathrm{N}$ sequestration in the warmer month of September. The years with warmest winter weather (2011 and 2015 to 2017) were also the years with highest performance of late-planted WCC.

The $\mathrm{NO}_{3}{ }^{-}$leaching reduction efficiency of WCC varied greatly according to planting date and species (table 6, figure 7). The difference in performance among planting dates was substantial, with early-planted species (10-year average) reducing leaching by an additional $8 \%, 13 \%$, and $18 \%$ compared to standard planting dates, and by an additional $27 \%, 35 \%$, and $38 \%$ relative to late planting dates, for rye, barley, and wheat, respectively (table 6). The increased performance of early-planted WCC results from increased access to climate conditions favorable to growth (warmer temperature and longer growing days) in the early days of autumn. In practice, cover crops benefit from being planted as soon as possible after row crop harvest, or even earlier using interseeding methods. The benefit of quick planting to utilize warm weather for growth while it is available is substantial, as fall temperatures quickly cool toward winter. For this reason, the MACS program increases payment rates to incentivize early planting dates.

The difference in performance among WCC species became more pronounced with later planting dates (table 6, figure 7), due to the greater cold tolerance of rye relative to barley and wheat. Rye WCC reduced $\mathrm{NO}_{3}^{-}$leaching by an additional 3\% and 7\%, respectively, over barley and wheat at the early planting date, an additional $8 \%$ and $17 \%$ at the standard planting date, and an 


\section{Figure 3}

Annual wintertime vegetation classification for cropland within the Tuckahoe Creek watershed from 2008 through 2017, based upon composite satellite Normalized Difference Vegetation Index (NDVI) threshold values for minimal, low, medium, and high levels of green vegetation.
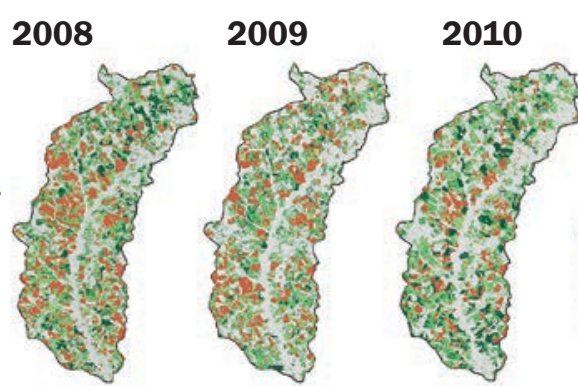

2011

\section{NDVI thresholds map}

-0.99 to 0.10 wet

0.10 to 0.29 minimal biomass

0.29 to 0.40 low biomass

0.40 to 0.53 medium biomass

0.53 to 0.99 high biomass

$510 \quad 20$ km

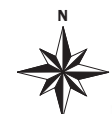

2012

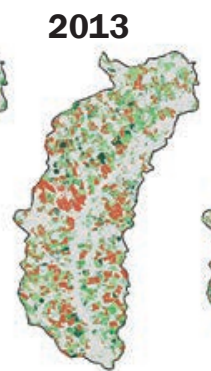

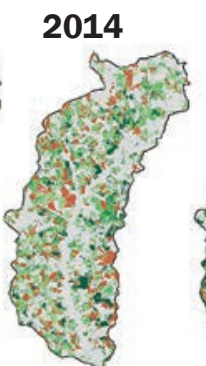

2015

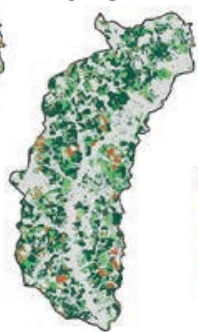

2016

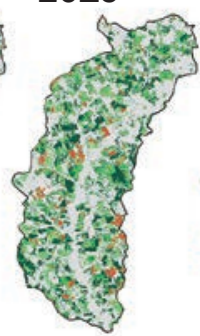

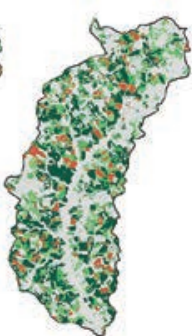

2017

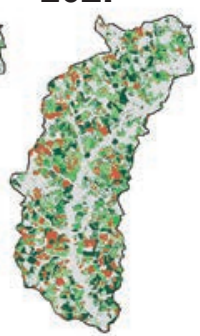

additional $12 \%$ and $18 \%$ at the late planting date. The difference among species performance (growth rate relative to growing degree accumulation) was established within the SWAT model (Yeo et al. 2014; Lee et al. 2016) based upon one year of remote sensing performance analysis reported by Hively et al. (2009), and it is likely that the relative contributions of wheat, barley, and rye vary somewhat depending on each year's climate. In practice, additional WCC species including triticale, forage radish, and rapeseed can also provide substantial water quality benefits, although these species were not modeled due to lack of sufficient input data.

Combining SWAT Model Output with Observed Trends in Cost-Share Enrollment. To arrive at an overall estimation of cover crop performance, the SWAT-derived estimates of annual WCC efficiency, segmented by species and planting date category, were combined with observed patterns of WCC implementation recorded by the MACS cost-share program database (tables 2 and 3 ). By combining 10-year average SWAT load reductions (table 6) with 10-year average MACS WCC implementation data (tables 2 and 3), the overall 10-year outcome of

\section{Figure 4}

Percentage of cropland falling within certain categories of wintertime vegetative cover, calculated from satellite Normalized Difference Vegetation Index (NDVI) vegetation analysis and separated by preceding summer crop type from Cropland Data Layer (CDL), including (a) percentage of crop type exhibiting nonminimal wintertime vegetation (NDVI > 0.29), and (b) percentage of crop type exhibiting medium-to-high levels of vegetation (NDVI > 0.40), Tuckahoe Creek watershed, 2008 to 2017.

(a)

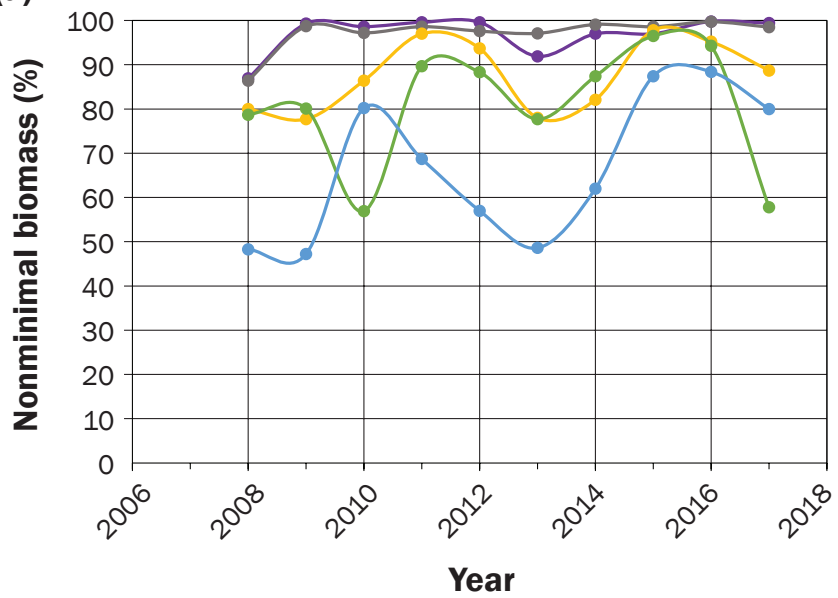

(b)

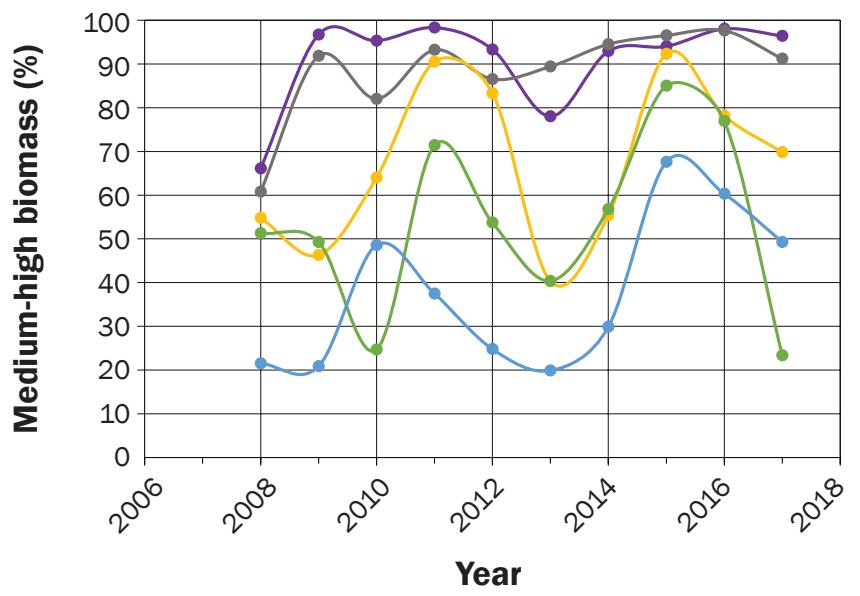




\section{Figure 5}

Percentage of cropland falling within certain categories of wintertime vegetative cover for (a) all row crops and (b) corn crops, calculated from satellite vegetation analysis, with growing degrees (base $4^{\circ} \mathrm{C}, \mathrm{GDD} 4$ ) accumulated between November 15 and March 1, Tuckahoe Creek watershed, 2008 to 2017.

(a)

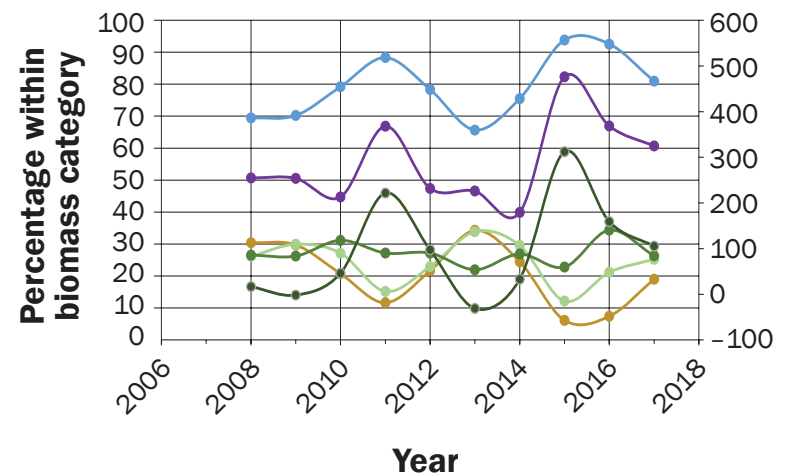

(b)

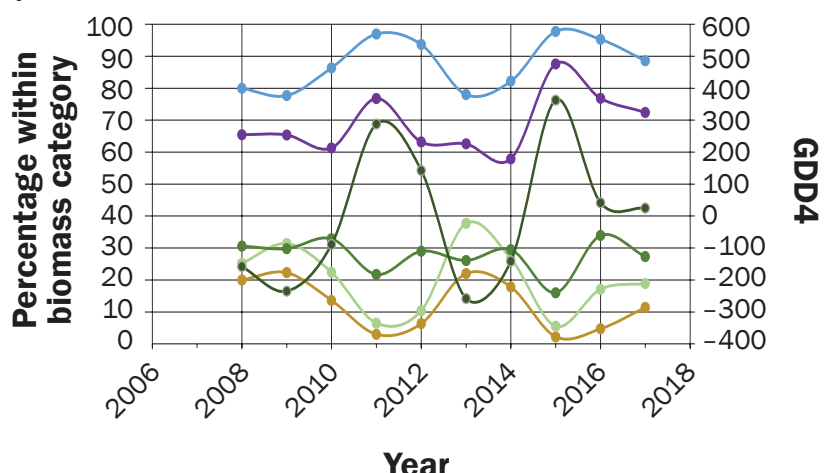

Legend

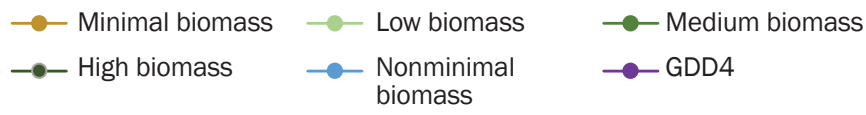

\section{Table 5}

Soil and Water Assessment Tool (SWAT) model estimates of annual variation in baseline nitrate leaching from cropland in the Upper Tuckahoe watershed, resulting from interannual variation in climate, using historically accurate weather input data. Baseline load ( $\mathrm{kg} \mathrm{N} \mathrm{ha}^{-1} \mathrm{nitrate}$ leaching from croplands) represents the no-cover-crop scenario. Data are reported for the SWAT simulation winter time period (e.g., "2008" = September 1, 2008, to March 31, 2009).

\begin{tabular}{|c|c|c|c|c|c|c|c|c|c|c|c|}
\hline Factor & 2008 & 2009 & 2010 & 2011 & 2012 & 2013 & 2014 & 2015 & 2016 & 2017 & Average \\
\hline $\begin{array}{l}\text { Baseline nitrate } \\
\text { leaching }(\mathrm{kg} \mathrm{N} \mathrm{ha-1})\end{array}$ & 19.7 & 35.8 & 25.3 & 20.1 & 28.5 & 30.9 & 27.6 & 26.6 & 20.5 & 27.0 & 26.2 \\
\hline $\begin{array}{l}\text { Precipitation }(\mathrm{cm}), \\
\text { Sept. } 1 \text { to Mar. } 31\end{array}$ & 41 & 81 & 44 & 43 & 63 & 62 & 59 & 56 & 54 & 47 & 55 \\
\hline Growing degrees, & 654 & 705 & 647 & 906 & 615 & 624 & 571 & 1,510 & 1,389 & 1,216 & 884 \\
\hline
\end{tabular}

Sept. 1 to Mar. 31

observed WCC implementation was estimated to be a $25 \%$ annual reduction in $\mathrm{N}$ leaching from cropland.

The 10-year average of observed WCC implementation was as follows: WCC planted on $41 \%$ of cropland with a distribution of $68.1 \%$ wheat $(14.7 \%$ early, $18.8 \%$ standard, and $34.7 \%$ late), $16.1 \%$ barley $(8.0 \%$ early, $6.5 \%$ standard, and $1.6 \%$ late), $7.2 \%$ rye (2.8\% early, $1.9 \%$ standard, and $2.6 \%$ late), and $8.6 \%$ miscellaneous species (assumed for these calculations to behave similarly to early-planted wheat, although data were not available to correctly model these minority species). Were the 10-year observed distribution of species and planting dates to be implemented on $100 \%$ of row crop fields, the reduction in cropland leaching would increase to $60 \%$.
In comparison, a best-case WCC management scenario of $100 \%$ early rye planted on $100 \%$ of cropland was estimated to reduce $\mathrm{N}$ loads by $85 \%$; a scenario of $100 \%$ late wheat planted on $100 \%$ of cropland reduced $\mathrm{N}$ loads by $40 \%$; a scenario of $100 \%$ early rye on $41 \%$ of cropland resulted in a $35 \%$ reduction; and a worst-case WCC management scenario of $100 \%$ late wheat on $41 \%$ of cropland resulted in a $16 \%$ reduction. If the observed 10-year distribution of species (68.1\% wheat, $16.1 \%$ barley, and $7.2 \%$ rye, plus $8.6 \%$ miscellaneous species modeled as early wheat) was planted on $100 \%$ of crop land, $100 \%$ within one of the date ranges, then reductions of $79 \%, 64 \%$, and $45 \%$ would be expected to result for early, standard, and late date ranges, respectively.

In 2016, the year of record with the most cover crop implementation, cover crops were planted on $64 \%$ of cropland (table 3). Using the observed ratio of WCC species planted in 2016 (76.5\% wheat, 8.4\% barley, and 6.9\% rye, plus $8.2 \%$ miscellaneous species modeled as early wheat; Soroka et al. 2019) reductions of $51 \%, 41 \%$, and $29 \%$ would be expected to result if all WCC were planted in either the early, standard, and late date ranges, respectively. Using the actual distribution of planting dates observed in 2016 (27\% early, 22\% standard, and 52\% late; Soroka et al. 2019) on $64 \%$ of row crop fields, a $38 \%$ reduction in $\mathrm{N}$ leaching loads was predicted to have resulted from WCC planted on farmland within the Upper Tuckahoe watershed in 2016.

\section{Summary and Conclusions}

The use of WCC has been identified by the Chesapeake Bay Program partner- 


\section{Figure 6}

(a) Percentage of long-term cropland in the Tuckahoe Creek watershed exhibiting medium-high levels of vegetation (NDVI > 0.4) calculated from satellite vegetation analysis, with growing degrees (base $4^{\circ} \mathrm{C}, \mathrm{GDD} 4$ divided by 5 for display purposes) accumulated between November 15 and March 1, for three time periods of increasing winter cover crop (WCC) implementation ( 1984 to $1997 ; 1998$ to $2009 ; 2010$ to 2017); and (b) relationship between the percentage of long-term cropland exhibiting medium-high levels of vegetation and accumulated wintertime growing degrees (GDD4) for three time periods of increasing WCC implementation.

(a)

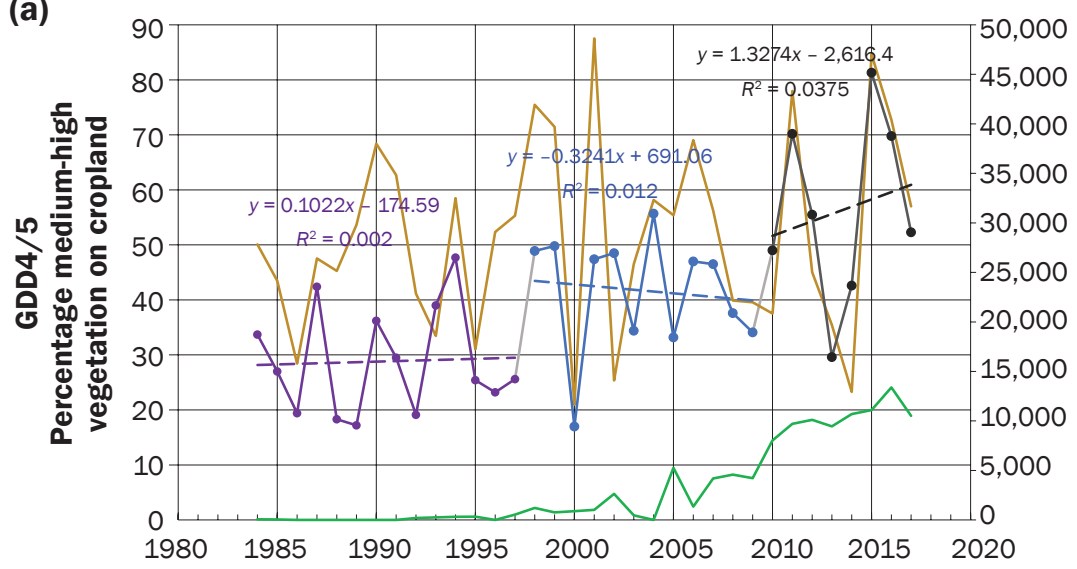

Legend $\rightarrow 1984$ to $1997-1998$ to $2009-2010$ to $2017-$ GDD4/5 - Cover crop

(b)

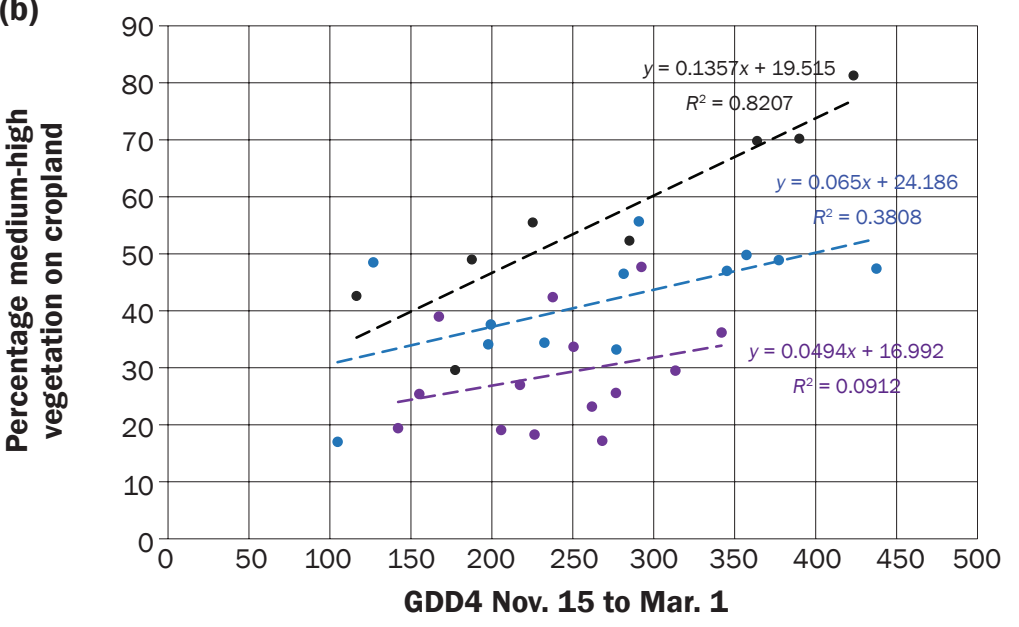

Legend
- 1984 to 1997
- 1998 to 2009
- 2010 to 2017
- Linear (1984 to 1997)
- - Linear (2010 to 2017)

ship as a critical management practice for reducing the loss of nutrients and sediments from farmland, and the planting of cover crops has been subsidized and promoted by the Maryland Department of Agriculture, resulting in widespread interest on the part of farmers. In the Tuckahoe Creek subwatershed of the Choptank River, cost-share enrollment records document that WCC were planted on $<3 \%$ of cropland prior to 1997, rising to $17 \%$ of row crop fields in $2008(27 \%$ of corn fields and 9\% of soybean fields), and that usage increased rapidly beginning in 2010 , rising to $64 \%$ of row crop fields by 2016 (89\% of corn fields and 46\% of soybean fields).

In the 10-year time period for which the CDL was available (2008 to 2017), wintertime growing conditions were the strongest driver of wintertime vegetation abundance, overwhelming the effects of WCC implementation, which was relatively high throughout most of the period. However, use of a long-term remote sensing data set (1984 to 2017) showed a highly significant increase in wintertime greenness associated with moderate (1998 to 2009) and high (2010 to 2017) levels of WCC implemen- tation against the background of climate variability. When applying multidate remote sensing techniques to WCC vegetation analysis, care must be taken to contextualize results within annual weather patterns, and to accurately represent the spatial distribution of management practices through time. Future efforts would benefit by incorporating a site-specific, process-based WCC growth model to simulate WCC nutrient dynamics in the context of soils and climate.

While WCC implementation is considered to be among the most effective best management practices for reducing nutrient and sediment loss from farmland, we know comparatively little about the interannual performance of WCC at the landscape scale. The novel combination of SWAT modeling with WCC growth parameters derived from satellite remote sensing, accurate climate data, and accurate WCC implementation records helped to address this question. From 2008 to 2017, observed levels of WCC implementation were estimated by the SWAT nutrient loading model to have reduced $\mathrm{NO}_{3}^{-}$leaching from cropland in the Upper Tuckahoe watershed by $25 \%$. Year-to-year simulated performance of WCC depended strongly on the weather, with warm winters resulting in a greener landscape, and wet winters resulting in increased $\mathrm{NO}_{3}^{-}$leaching. Using the distribution of WCC species, planting dates, and percentage of cropland enrolled in WCC that was observed in 2016 (the year with highest WCC cost-share enrollment), the SWAT model predicted a reduction of $38 \%$ in annual wintertime $\mathrm{NO}_{3}^{-}$leaching from cropland.

The increase in the use of WCC over the 10-year study period and the associated increase in estimated reductions in $\mathrm{N}$ leaching were substantial. However, in the Tuckahoe Creek watershed, as elsewhere on the Eastern Shore of Chesapeake Bay, lateplanted wheat composed a large portion of the cover crop implementation $34.7 \%$ of all WCC planted between 2008 and 2017), with considerably diminished environmental effectiveness relative to earlier planting dates and more cold-tolerant WCC species. There is a clear opportunity to increase the effectiveness of WCC by shifting toward earlier plantings of the most effective WCC species, planted in a manner that establishes abundant growth prior to the onset of winter.

This study demonstrated that there are several avenues to increasing the envi- 
Table 6

Annual variation in simulated winter cover crop performance (reduction in nitrogen leaching from crop fields) in Soil and Water Assessment Tool (SWAT) model output for Upper Tuckahoe watershed, resulting from interannual variation in climate, using historically accurate weather input data. Cover crop species performance was simulated according to planting date category (SWAT simulation planting dates for early = Oct. 3 ; standard = Oct. 17; late $=$ Nov. 2), and scenarios assumed that $100 \%$ of cropland was planted to each unique combination of cover crop species and planting date. Data are reported for the SWAT simulation winter time period (e.g., "2008" = September 1, 2008, to March 31, 2009), with relative efficiencies calculated in comparison to "early rye" performance.

\begin{tabular}{|c|c|c|c|c|c|c|c|c|c|c|c|c|}
\hline $\begin{array}{l}\text { Cover crop } \\
\text { scenario }\end{array}$ & \multicolumn{11}{|c|}{ Percentage reduction from baseline (\%) } & $\begin{array}{l}\text { Relative } \\
\text { efficiency }\end{array}$ \\
\hline Early rye & 96 & 76 & 66 & 93 & 88 & 80 & 84 & 83 & 88 & 91 & 85 & 1.00 \\
\hline Early wheat & 80 & 65 & 61 & 92 & 81 & 74 & 77 & 81 & 85 & 89 & 78 & 0.92 \\
\hline Standard rye & 77 & 64 & 59 & 89 & 77 & 74 & 75 & 80 & 82 & 87 & 77 & 0.90 \\
\hline Late rye & 59 & 48 & 41 & 75 & 38 & 58 & 43 & 74 & 75 & 70 & 58 & 0.68 \\
\hline Late barley & 44 & 38 & 30 & 63 & 29 & 43 & 32 & 65 & 67 & 54 & 46 & 0.55 \\
\hline Late wheat & 39 & 32 & 25 & 55 & 26 & 37 & 28 & 54 & 58 & 45 & 40 & 0.47 \\
\hline
\end{tabular}

ronmental benefits associated with WCC: (1) plant earlier, (2) plant effective species, and (3) increase implementation area. Although beyond the scope of this study, it is also important to use appropriate planting methods and equipment that achieve good establishment, to use improved WCC seed, and to target physical and temporal niches within the landscape and crop rotation that have high risk of $\mathrm{N}$ leaching.

\section{Acknowledgements}

This project was supported by the US Geological Survey's Land Change Science Program within the Land Resources Mission Area; the USDA's Natural Resources Conservation Service Conservation Effects Assessment Project Watershed Assessment Studies, Agricultural Research Service National Program 211, and Lower Chesapeake Long Term Agricultural Research (LTAR) program; and by the Maryland Department of Agriculture, Department of Resource Conservation.

\section{Figure 7}

Ten-year average (2008 to 2017) of nitrate leaching under the baseline (NoWCC) and nine winter cover crop (WCC) scenarios during the winter period (Sept. 1 to Mar. 31): early wheat (WE), early barley (BE), early rye (RE), standard wheat (WS), standard barley (BS), standard rye (RS), late wheat $(\mathrm{WL})$, late barley $(\mathrm{BL})$, and late rye (RL). Error bars indicate one standard deviation from 10-year mean.

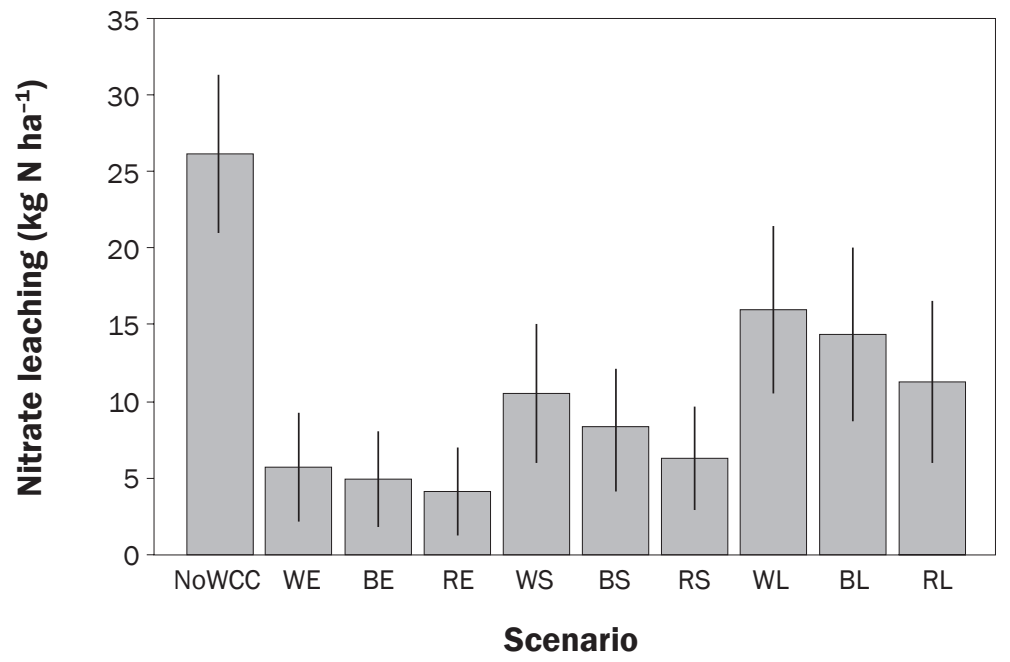


Remote Sensing of Environment 202:1-27, https://doi. org/10.1016/j.rse.2017.06.031.

Hively, W.D., M. Lang, G.W. McCarty, J. Keppler, A. Sadeghi, and L.L. McConnell. 2009. Using satellite remote sensing to estimate winter cover crop nutrient uptake efficiency. Journal of Soil and Water Conservation 64(5):303-313, https://doi.org/10.2489/jswc.64.5.303.

Hively, W.D., C.J. Hapeman, L.L. McConnell, T.R. Fisher, C.P. Rice, G.W. McCarty, A.M. Sadeghi, D.R. Whitall, P.M.Downey, G.T. Niño de Guzmán, K. Bialek-Kalinski, M.W. Lang, A.B. Gustafson, A.J. Sutton, K.A. Sefton, and J.A. Harman Fetcho. 2011. Relating nutrient and herbicide fate with landscape features and characteristics of 15 sub-watersheds in the Choptank River watershed. Science of the Total Environment 409(19):3866-3878, https://doi.org/10.1016/j.scitotenv.2011.05.024.

Hively, W.D., S.W. Duiker, G.W. McCarty, and K. Prabhakara. 2015. Remote sensing to monitor cover crop adoption in southeastern Pennsylvania. Journal of Soil and Water Conservation 70(6):340-352, https://doi.org/10.2489/ jswc70.6.340.

Hively, W.D., B. Lamb, C.S. Daughtry, G.W. McCarty, and M. Quemada. 2018. Mapping crop residue and tillage intensity using WorldView-3 satellite shortwave infrared residue indices. Remote Sensing 10(10):1657, https:// doi.org/10.3390/rs10101657.

Hively, W.D., J. Shermeyer, B.T. Lamb, C.S. Daughtry, and M. Quemada. 2019. Mapping crop residue by combining Landsat and Worldview 3 satellite imagery. Remote Sensing 11(16):1857, https://doi.org/10.3390/ rs11161857.

Huang, C., Y. Peng, M. Lang, I.-Y.Yeo, and G. McCarty. 2014. Wetland inundation mapping and change monitoring using Landsat and airborne LiDAR data. Remote Sensing of Environment 141:231-242, http://doi. org/10.1109/JSTARS.2013.2265191.

Hunt, E.R., W.D. Hively, S.J. Fujikawa, D.S. Linden, C.S.T. Daughtry, and G.W. McCarty. 2010. Acquisition of NIR-green-blue digital photographs from unmanned aircraft for crop monitoring. Remote Sensing 2(1):290305, http://doi.org/10.3390/rs2010290.

Hunt, E.R., W.D. Hively, G.W. McCarty, C.S.T. Daughtry, P.J. Forrestal, R.J. Kratochvil, J.L. Carr, N.F. Allen, J.R. FoxRabinovitz, and C.D. Miller. 2011. NIR-green-blue high-resolution digital images for assessment of winter cover crop biomass. GIScience and Remote Sensing 48:86-98, https://doi.org/10.2747/1548-1603.48.1.86.

Hunt, P., J. Miller, T. Ducey, M.W. Lang, A. Szogi, and G.W. McCarty. 2014. Denitrification in natural, restored and converted wetlands of the Delmarva Region of the US. Ecological Engineering 71:438-447.

Jones, N., G.R. Evenson, D. McLaughlin, M.K. Vanderhoff, M.W. Lang, G.W. McCarty, H.E. Golden, C.R. Lane, and L. Alexander. 2018. Estimating restorable wetland water storage at landscape scales. Hydrological Processes 32(2):305-313, https://doi.org/10.1002/hyp.11405.
Lang, M., O. McDonough, G.W. McCarty, R. Oesterling, and B. Wilen. 2012a. Enhanced detection of wetland-stream connectivity using LiDAR. Wetlands 32:461-473.

Lang, M., G.W. McCarty, R. Oesterling, and I.-Y. Yeo. 2012b. Topographic metrics for improved mapping of forested wetlands. Wetlands 33:141-155, doi:10.1007/ s13157-012-0359-8.

Lee, S., I.-Y. Yeo, A.M. Sadeghi, G.W. McCarty, W.D. Hively, and M.W. Lang. 2016. Impacts of watershed characteristics and crop rotations on winter cover crop nitrate-nitrogen uptake capacity within agricultural watersheds in the Chesapeake Bay Region. PLOS One 11(6):e0157637, https://doi.org/10.1371/journal. pone. 0157637.

Lee, S., I.-Y.Yeo, M.W. Lang, G.W. McCarty, A.M. Sadeghi, A.S. Sharifi, H. Jin, and Y. Liu. 2017a. Improving the catchment scale wetland modeling using remotely sensed data. Environmental Modelling and Software 122: 104069, https://doi.org/10.1016/j.envsoft.2017.11.001.

Lee, S., A.M. Sadeghi, I.-Y.Yeo, G.W. McCarty, W.D. Hively, M.W.Lang, and A. Sharif. 2017b.Assessing climate change impacts on winter cover crop nitrate uptake efficiency on the Coastal Plain of the Chesapeake Bay Watershed using SWAT model. ASABE Annual International Meeting 1700174. St. Joseph, MI: American Society of Agricultural and Biological Engineers, https://doi. org/10.13031/aim.201700174.

Lee, S., A.M. Sadeghi, I.-Y. Yeo, G.W. McCarty, and W.D. Hively. 2017c. Assessing the impacts of future climate conditions on the effectiveness of winter cover crops in reducing nitrate loads into the Chesapeake Bay watersheds using the SWAT model. Transactions of the ASABE 60(6), https://doi.org/10.13031/trans.12390.

Lee, S., I.-Y.Yeo, W.M. Lang, M.A. Sadeghi, W.G. McCarty, E.G. Moglen, and G. Evenson. 2018a. Assessing the cumulative impacts of geographically isolated wetlands on watershed hydrology using the SWAT model coupled with improved wetland modules. Journal of Environmental Management 223:37-48.

Lee, S., I.-Y.Yeo, A.M. Sadeghi, G.W. McCarty, W.D. Hively, M.W. Lang, and A. Sharifi. 2018b. Comparative analyses of hydrological responses of two adjacent watersheds to climate variability and change scenarios using SWAT model. Hydrology and Earth System Sciences 22:689708, https://doi.org/10.5194/hess-2017-178.

Lee, S., C. Wallace, M.A. Sadeghi, W.G. McCarty, H. Zhong, and I.-Y. Yeo. 2018c. Impacts of Global Circulation Model (GCM) bias and WXGEN on modeling hydrologic variables. Water 10(6):764, https://doi. org/10.3390/w10060764.

Lee, S., M.A. Sadeghi, W.G. McCarty, C. Baffaut, S. Lohani, A. Thompson, I.-Y. Yeo, and C. Wallace. 2018d. Assessing the suitability of the Soil Vulnerability Index (SVI) classification scheme using the SWAT model. CATENA 167:1-12, https://doi.org/10.1016/j. catena.2018.04.021.
Li, X., G.W. McCarty, M.W. Lang, T. Ducey, P. Hunt, and J. Miller. 2017b. Topographic and physicochemical controls on soil denitrification in prior converted croplands located on the Delmarva Peninsula, USA. Geoderma 309:41-49, https://doi.org/10.1016/j. geoderma.2017.09.003.

McCarty, G.W., L.L. McConnell, C.J. Hapeman, A. Sadeghi, C. Graff, W.D. Hively, M.W. Lang, T.R. Fisher, T. Jordan, C.P. Rice, E.E. Codling, D. Whitall, A. Lynn, J. Keppler, and M.L. Fogel. 2008. Water quality and conservation practice effects in the Choptank River watershed. Journal of Soil and Water Conservation 63(6):461-474, https://doi.org/10.2489/jswc.63.6.461.

McCarty, G.W., C.J. Hapeman, C.P. Rice, W.D. Hively, L.L. McConnell, A.M. Sadeghi, M.W. Lang, D.R. Whitall, K. Bialek, and P. Downey. 2014. Metolachlor metabolite (MESA) reveals agricultural nitrate-N fate and transport in Choptank River watershed. Science of the Total Environment 473-474:473-482, https://doi. org/10.1016/j.scitotenv.2013.12.017.

Neitsch, S.L., J.G. Arnold, J.R. Kiniry, and J.R. Williams. 2011. Soil and Water Assessment Tool Theoretical Documentation. Version 2009. College Station, TX: Texas Water Resources Institute.

Nino De Guzman, G.T., C.J. Hapeman, K. Prabhakara, E.E. Codling, D.R. Shelton, C. Rice, W.D. Hively, G.W. McCarty, and A. Torrents. 2012. Potential pollutant sources in a Choptank River sub-watershed: Influence of agricultural and residential land use and aqueous and atmospheric sources. Science of the Total Environment 430:270-279.

Prabhakara, K., W.D. Hively, and G.W. McCarty. 2015. Evaluating the relationship between biomass, percent ground cover and remote sensing indices across six winter cover crop fields in Maryland, United States. International Journal of Applied Earth Observation and Geoinformation 39:88-102, doi:10.1016/j. jag.2015.03.002.

Quemada, M., W.D. Hively, C.S.T. Daughtry, B.T. Lamb, and J. Shermeyer. 2018. Improved crop residue cover estimates obtained by coupling spectral indices for residue and moisture. Remote Sensing of Environment 2018:206:33-44, doi:10.1016/j.rse.2017.12.012.

Sanford,W.E., and J.P. Pope. 2013. Quantifying groundwater's role in delaying improvements to Chesapeake Bay water quality. Environmental Science and Technology 47(23):13330-13338.

Sharifi, A., M.W. Lang, G.W. McCarty, A.M. Sadeghi, S. Lee, H. Yen, M.C. Rabenhorst, J. Jeong, and I.-Y. Yeo. 2016. Improving model prediction reliability through enhanced representation of wetland soil processes and constrained model auto calibration: A paired watershed study. Journal of Hydrology 541:1088-1103.

Sharma, P., A. Singh, C. Singh Kahlon, A. Singh Brar, K.K. Grover, M. Dia, and R.L. Steiner. 2018. The role of cover crops towards sustainable soil health and agriculture: A review paper. American Journal of Plant 
Sciences 9(9):1935-1951, https://doi.org/10.4236/ ajps.2018.99140.

Soroka,A.,W.D. Hively, and B.T.Lamb. 2019. Landsat-derived wintertime greenness datasets and results from cover crop performance analysis within the Tuckahoe Creek watershed, Maryland, from 1984 to 2017. US Geological Survey data release. Washington, DC: US Geological Survey. https://doi.org/10.5066/P9OZ6ND0.

Staver, K., R. Brinsfield, and J.C. Stevenson. 1989. The effect of best management practices on nitrogen transport into Chesapeake Bay. Proceedings of the 2nd Pan-American Regional Conference of the International Commission on Irrigation and Drainage, Ottawa, Canada, June 8-9, 1989. Denver, CO: US Committee on Irrigation and Drainage, Denver.

Sun, L., M.C.Anderson, F. Gao, C. Hain, J.G.Alfieri,A. Sharifi, G.W. McCarty, Y. Yang, W.P. Kustas, and L. McKee. 2017. Investigating water use over the Choptank River watershed using a multisatellite data fusion approach. Water Resources Research 53:5298-5319, https://doi. org/10.1002/2017WR020700

Tucker, C. 1979. Red and photographic infrared linear combinations for monitoring vegetation. Remote Sensing of Environment 8:127-150.

University of Maryland. 2018. Weather Data for the Wye REC. College Park, MD: University of Maryland, College of Agriculture and Natural Resources. https:// agnr.umd.edu/research/resources/weather-data/ weather-data-wye-rec

USDA NASS (National Agricultural Statistics Service). 2019. CropScape: Cropland Data Layer. Washington, DC: USDA National Agricultural Statistics Service. https:// nassgeodata.gmu.edu/CropScape/.

Whitall, D., W.D. Hively, A.K. Leight, C.J. Hapeman, L.L. McConnell, T. Fisher, E.E. Codling, C. Rice, G.W McCarty, and A.M. Sadeghi. 2010. Pollutant fate and spatio-temporal variability in the Choptank River estuary: Factors influencing water quality. Science of the Total Environment 408:2096-2108.

Yeo, I.-Y., S. Lee, A.M. Sadeghi, P.C. Beeson, W.D. Hively, G.W. McCarty, and M.W. Lang. 2014. Assessing winter cover crop nutrient uptake efficiency using a water quality simulation model. Hydrology and Earth System Sciences 18:5239-5253.

Yeo, I.-Y., M. Lang, S. Lee, G.W. McCarty, A.M. Sadeghi, O. Yetemen, and C. Huang. 2019a. Mapping the landscapelevel hydrological connectivity of headwater wetlands to downstream waters: A geospatial modelling approachPart I. Science of the Total Environment 653:1546-1556, 10.1016/j.scitotenv.2018.11.238

Yeo, I.-Y., S. Lee, M. Lang, O. Yetemen, G.W. McCarty, A.M. Sadeghi, and G. Evenson. 2019b. Mapping landscapescale hydrological connectivity of headwater wetlands to downstream water: A catchment modelling approach - Part 2. Science of the Total Environment 653:15571570, 10.1016/j.scitotenv.2018.11.237. 